\title{
Childhood Obesity Declines Project: Highlights of Community Strategies and Policies
}

\author{
Jan Jernigan, PhD,' Laura Kettel Khan, PhD, Carrie Dooyema, MSN, MPH, RN, \\ Phyllis Ottley, $\mathrm{PhD}^{2}$, Carole Harris, $\mathrm{PhD}^{3}$, Nicola Dawkins-Lyn, $\mathrm{MPH}^{3}$, \\ Tina Kauh, $\mathrm{PhD}^{4}$ and Deborah Young-Hyman, $\mathrm{PhD}^{5}$
}

\section{Abstract}

Background: The social ecological model (SEM) is a framework for understanding the interactive effects of personal and environmental factors that determine behavior. The SEM has been used to examine childhood obesity interventions and identify factors at each level that impact behaviors. However, little is known about how those factors interact both within and across levels of the SEM.

Methods: The Childhood Obesity Declines (COBD) project was exploratory, attempting to capture retrospectively policies and programs that occurred in four communities that reported small declines in childhood obesity. It also examined contextual factors that may have influenced initiatives, programs, or policies. Data collection included policy and program assessments, key informant interviews, and document reviews. These data were aggregated by the COBD project team to form a site report for each community (available at www.nccor.org/projects/obesity-declines). These reports were used to develop site summaries that illustrate how policies, programs, and activities worked to address childhood obesity in each study site.

Results/Conclusions: Site summaries for Anchorage, AK; Granville County, NC; Philadelphia, PA; and New York City, NY, describe those policies and programs implemented across the levels of the SEM to address childhood obesity and examine interactions both across and within levels of the model to better understand what factors appear important for implementation success.

Keywords: obesity prevention; policy; population-based interventions; social ecological model

\section{Introduction}

$\mathbf{T}$ he social ecological model (SEM) is a framework for understanding the interactive effects of personal and environmental factors that determine behavior; it describes those factors that influence health at the individual, interpersonal, organizational, community, and policy levels. ${ }^{1}$ The SEM has been the focus of health promotion programs for several decades and research has shown that addressing population-based health issues is most effective when tackled from multiple levels of influence.

A growing literature has examined the complex problem of childhood obesity using the $\mathrm{SEM}^{2-6}$ and has identified a number of interventions/strategies at each level of the model that have contributed to achievements in addressing childhood obesity. ${ }^{2,7-10}$ A better understanding of how these different strategies operate at each level, and how interactions both across and within levels of the SEM influence success can inform future interventions.

Other articles in this special issue documented those policies implemented at the state level that may influence obesity rates, ${ }^{11}$ programs in each community that were thought to have influenced childhood obesity rates, and factors that may have been important contributors to success in four communities studied with childhood obesity declines (COBD). ${ }^{12}$ This article maps those policies and programs

\footnotetext{
'Division of Nutrition, Physical Activity, and Obesity, Centers for Disease Control and Prevention, Atlanta, GA.

${ }^{2}$ Division of Violence Prevention, Centers for Disease Control and Prevention, Atlanta, GA.

${ }^{3}$ Division of Health, Research, Informatics, and Technology, ICF, Atlanta, GA.

${ }^{4}$ Research-Evaluation-Learning Unit, Robert Wood Johnson Foundation, Princeton, NJ.

${ }^{5}$ Office of Behavioral and Social Sciences Research, National Institutes of Health, Bethesda, MD.
} 
across the levels of the SEM to address childhood obesity and examines interactions both across and within levels of the model to better understand how they might influence implementation success.

\section{Methods}

The COBD project methodology ${ }^{13}$ involved systematically exploring policies and programs that may have contributed to reported declines in childhood obesity in four sites: Anchorage, AK; Granville County, NC; New York City, NY; and Philadelphia, PA. COBD were noted in these communities between 2003 and 2012. The study was exploratory and attempted to capture retrospectively policies and programs that occurred in these communities, along with contextual factors that may have influenced initiatives, programs, or policies. Data collection included policy and program assessments, key informant interviews, and document reviews. The COBD project team aggregated these data to form a site report for each community (available at www.nccor.org/projects/obesity-declines). These reports were used to develop site summaries that illustrate how policies, programs, and activities worked to address childhood obesity in each study site.

\section{Results}

The national policy landscape, during the time period of noted obesity declines, is described. It provides context for understanding state and local policies and practices. Next, summaries for each site provide an overview of the different policies and programs identified during the site visit interviews, which were undertaken to improve child nutrition and physical activity (PA). Each summary describes the range of policies and programs implemented in various settings at the local level, including Early Child and Education (ECE), schools, and the community at large. These summaries also include examples of interactions across and within levels of the SEM, and how these interactions may have contributed to successful implementation through buyin and engagement, greater efficiencies, and/or leveraged resources.

Each site summary also has an accompanying figure (Fig. 2) that reflects the range of policies and programs implemented across the levels of the SEM. Included are those that have the potential for the largest reach and influence on healthy eating or active living behaviors. Focal state and local policies and programs that directly targeted an entire school district or organizational settings, such as ECE centers, were prioritized, along with other communitybased programs that appeared to support and reinforce them. These include state and local policies that were not identified during the site visit but are summarized in this supplement. ${ }^{11}$ Temporal and/or efforts that targeted a single or specific organizational group were not included on the site's figure.

Given the concentric circles within the SEM model, placement of policies and programs for each site figure is

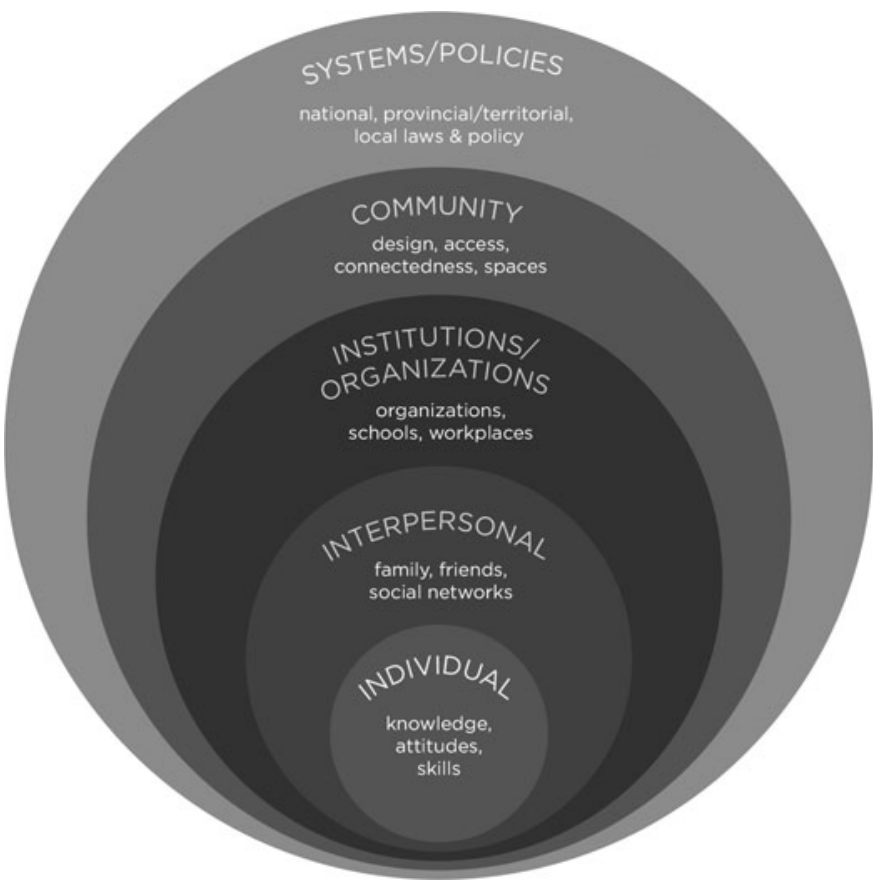

Figure 1. The social ecological model.

organized similarly with community stakeholder policies or activities on the top left and topical food system and built environment programs on the top right. Community system level policies and programs (e.g., healthcare, child care, and schools) are represented on the lower half of the figure. Although placement is designed to reflect where specific policies and programs are implemented and influence behavior, each site figure may look different based on the extent to which policies and programs are designed to reach each layer of the SEM, the partners and organizations involved, and policy mandates. The size of the circle does not signify the potential reach or influence of a particular strategy. It is simply sized to touch the layers of the SEM model involved. Some circles are placed behind another to indicate a closely related effort or component of a larger overall strategy or initiative. The complexity of interactions and layering for any given policy or program is not reflected in these figures. They represent our best attempt to describe, as simply as possible, the range of strategies that occurred in each site and is not a precise representation of all the possible interactions.

\section{National}

During the time period from 2003 to 2012, when all four communities recorded COBD, several notable Federal policies were implemented. Each site was equally exposed to national legislation to address obesity by addressing nutrition and PA for young people. First, in 2004, Reauthorization of the Child Nutrition and WIC Act included a requirement that all local education agencies participating in the National School Lunch Program establish a local wellness policy by the start of the 2006-2007 school 

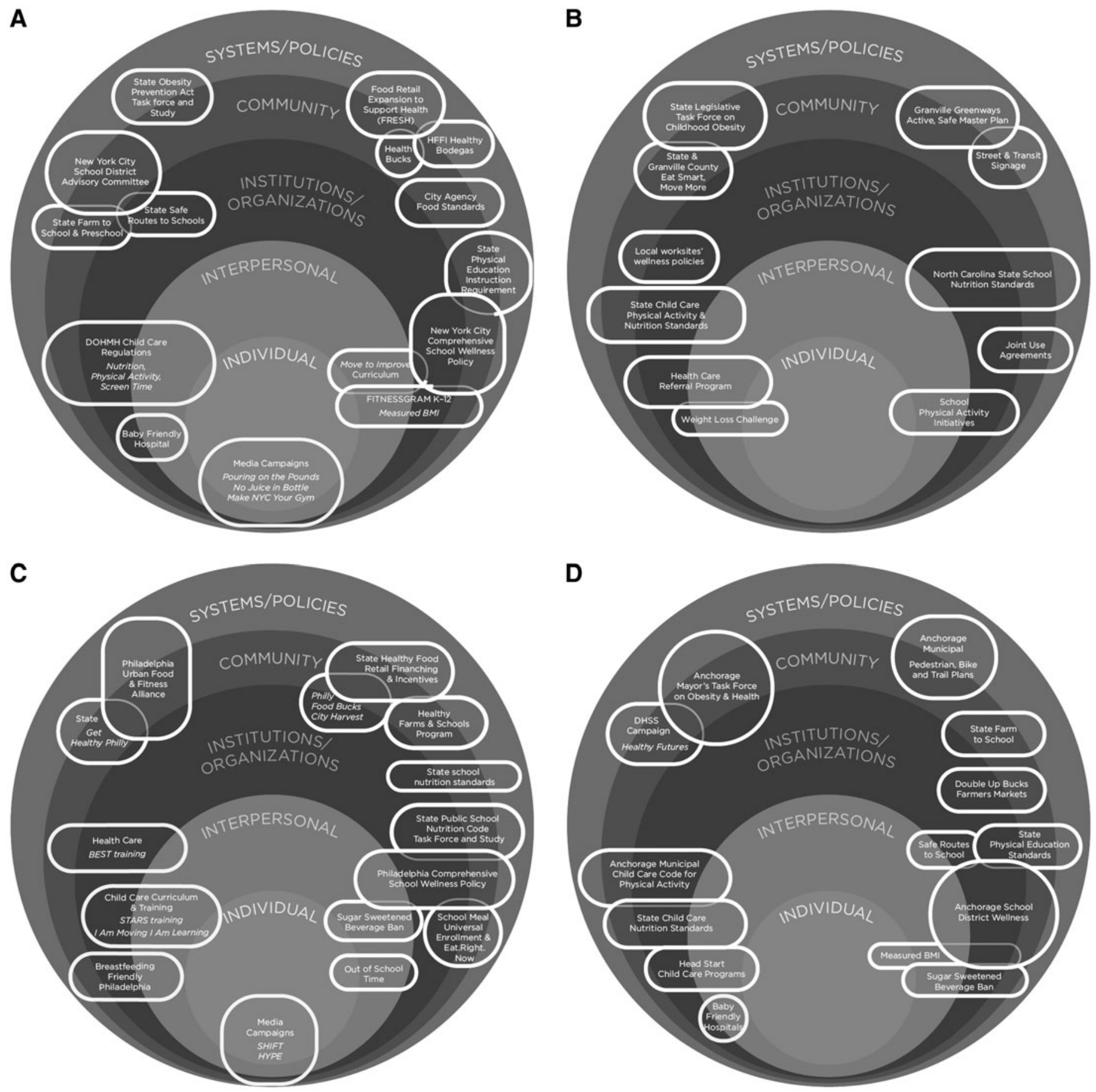

Figure 2. Strategies and initiatives relative to the social ecological model for: (A) New York, NY; (B) Granville County, NC; (C) Philadelphia, PA; and (D) Anchorage, AK.

year. ${ }^{14,15}$ It also emphasized that the majority of schools participating in the Fresh Fruit and Vegetable Program (FFVP) should be low income and provided funds for districts and schools related to farm-to-school programs as well as nutrition education. In 2007, Federal legislation passed addressing requirements for the Child and Adult Care Food Program (CACFP), including standards for the nutritional content of foods served and portion sizes. ${ }^{14,15}$
CACFP funding to the USDA supported centers in increasing PA and decreasing sedentary time through this legislation. Lastly, the Healthy Hunger-Free Kids Act, passed in 2010, reauthorized several child nutrition programs, outlined standards for the nutritional content of foods and beverages sold outside the school meals program, and updated nutrition standards for school meals. ${ }^{14,15}$ 
New York City, NY

In New York City, a statistically significant obesity decline was noted in children in grades K-6 from 20062007 to 2010-2011, with the largest decrease found in children of ages 5-6 years. ${ }^{16}$ The prevalence of obesity had a relative decline of 5.5\% $(p<0.001)$ between 2006-2007 (21.9\%) and 2010-2011 (20.7\%).

School setting. Between 2004 and 2006, the New York City school district implemented several programs that could have had an impact on obesity declines. The Universal Free Breakfast program, restricted unhealthy beverages and snacks in meals and vending, promoted fresh fruits and vegetables through the federally funded FFVP, introduced SPARK physical education (PE) training and conducted obesity screening programs using BMI. In 2009, PA requirements in New York City's elementary schools were revised to quantify the amount of time students engaged in PA.

Community. Policies and programs in the ECE and school settings were augmented by community-based initiatives that helped to reinforce healthy habits. At the community level, New York City implemented the Health Bucks program that was a farmers-market-based initiative that provided financial incentives to low-income families for purchasing fresh fruits and vegetables. In addition, the Healthy Bodega program increased access to healthy food in high poverty areas of the city. In 2008, New York City adopted a number of policies that improved the nutrition landscape, including a change in the city health codes for the adoption of food nutrition standards in government and public places, and local legislation establishing mobile vendors who sell fruits and vegetables through the Green Carts program.

Other community-based programs designed to support healthy eating and active living include calorie counts on all menu boards and menus; Mobile Markets that provided free produce and nutrition information; and the FRESH program that provided tax incentives for grocery stores and small markets to relocate in low-income areas as long as they stock foods that meet the city food standards. PA examples include Play Streets, a community-sponsored event where streets are closed to automobile traffic and opened for walking and cycling to promote PA; and Schoolyards to Playground, a program that opens the school playgrounds to the community to promote PA.

Interaction within city government agencies: implementation efficiency and buy-in. Both the New York City mayor and health commissioner at the time were committed to reducing the rates of obesity among New Yorkers overall, but made focused investments in strategies to impact childhood obesity. As a result of their interest and commitment, the city leaders encouraged city agencies to work together for greater reach and community engagement. This was perceived by stakeholders to facilitate and encourage health-promoting policies within and across agencies, and produced efficiencies through cross-agency implementation.

One example is the interaction between the health department and the Department of Education (DOE) in implementing the Move-to-Improve (MTI) program. MTI originated with the SPARK program, which trained PE teachers to raise their skill level for PE. The health department created MTI, which is more New York City centric for small classroom space, when city council funds no longer supported SPARK. The health department developed and pilot-tested the program, and conducted initial evaluations. Once the program was finalized, it was handed over to the DOE for implementation in the school district. Because the MTI program is not mandatory, participation depended on school principals and teachers to encourage and support it. The curriculum was free and schools with $85 \%$ teacher participation received $\$ 500$ in PE equipment and materials. Teachers were paid to be trained, which increased program participation, and Excellence in School Wellness Awards were given to schools that had at least $50 \%$ teacher participation. In addition, the health department and DOE partnered with the Teacher's Union that promoted the program among its union members.

\section{Granville County, NC}

Granville County saw significant declines (7.0\%; $p=0.001)$ in childhood obesity rates for children aged 2-4 years between $2009(22.7 \%)$ and $2012(15.7 \%){ }^{17}$

ECE settings. Before and during the period of noted COBD, Granville County implemented a number of initiatives in the child care setting. Between 2009 and 2010, the North Carolina Child Care Commission created licensing requirements related to $\mathrm{PA}$ and nutrition that impacted children in Head Start, pre-K, and licensed child care centers. To support implementation of the policies, the state and local health departments provided training and education to ECE staff to help implement the new standards. ECE facility cooks were taught how to cook foods that would meet the child care nutrition guidelines, and registered dieticians were available to review menus and work with ECE cooks in the county. Similar training and education efforts were undertaken around the new PA requirements for children in ECE to help teachers and staff implement increased PA time for young children.

Community. A number of initiatives at the state and county level increased opportunities for healthy eating and PA. Eat Smart, Move More (ESMM) was a state health department initiative created in 2002 with the release of three blueprint plans by the ESMM Leadership Council. The council formalized these plans through the development of ESMM: North Carolina's plan to prevent overweight, obesity, and related chronic diseases: 2007-2012, the state's 5-year obesity prevention plan, which supported all counties through resources and trainings to implement 
selected strategies. Granville Greenways, designed to increase opportunities for PA and active transport particularly in the area around schools, was initiated in 2004. With funding from the ESMM state campaign $(\sim \$ 20,000)$, the Granville County Health Department gave out minigrants that provided additional support for local organizations to implement their own environmental change interventions. Granville County also implemented a systematic screening process to identify children who were overweight or had obesity or were at risk in the county's Medicaid clinic.

Interaction between municipal governments: leveraging resources. Granville Greenways was a strategy designed to increase awareness of the importance of healthy living and to increase PA among residents. It also was a prime example of how working collaboratively both within and across levels of the SEM can promote efficiency and help leverage resources for successful program implementation. In 2008, the Granville County Board of Commissioners approved the Granville Greenways Master plan and appointed a multijurisdictional advisory council made up of members from each municipal government in the county, each of whom developed a separate pedestrian or bike plan. Leaders of the initiative made it a priority to involve and create partnerships with a multidisciplinary group of people throughout the county with experience in grant writing, construction, transportation, and planning. Working collaboratively, the council was able to leverage resources to improve the physical environment. For example, when one municipality developed a grant that was successful, it would share the proposal with other municipalities; when new grants were being drafted, a team was available to support the municipality applying for funding with grant reviews and writing assistance. As a result, it was estimated that the county was able to bring in nearly $\$ 8.1$ million in grant funding as a result of the master plan and subsequent municipal-level plans.

\section{Philadelphia, PA}

Statistically significant declines in obesity among K-8 grade students in public schools operated by the School District of Philadelphia (SDP) were identified between the 2006-2007 and 2009-2010 school years. Obesity declined from $21.5 \%$ to $20.5 \%$ over this time, representing a $4.8 \%$ relative decrease $\left(7.7 \%\right.$ for severe obesity). ${ }^{18}$

School setting. At the local level, the SDP was the "first" to implement a number of initiatives that may have served as the foundation for the declines noted. Although obesity declines in the SDP were documented beginning in 2006, several policies had been in place for years that impacted nutrition within the school setting. In 1991, the SDP launched a Universal Feeding Pilot program, the first school district in the country allowed to do so by the USDA. Since 1999, the SDP has implemented EAT.RIGHT.NOW (ERN), a statewide program that uses USDA Supplemental Nutrition Assistance Program Education (SNAP-Ed) fund- ing to provide nutrition education to individuals and families who are eligible to receive SNAP benefits. In 2004, the SDP became one of the first school districts in the country to remove all sodas and sugar-sweetened beverages from vending machines in public schools, reaching all students in $\mathrm{K}-12$.

The Comprehensive Districtwide School Wellness Policy went into effect in 2006 and provided a comprehensive approach to childhood wellness. The policy requires coordinated wellness councils as well as requirements for both nutrition and PA standards and education. Beginning in 2008, the City of Philadelphia Department of Human Services launched its Healthy Kids, Healthy Communities project. This resulted in guidelines to improve the nutrition and PA environment for children in school-based programs taking place outside of normal school hours. During this time, additional programs for schools were implemented, including programs such as the Pennsylvania farm to school initiative, and Healthy Farms and Healthy Schools, which provided grants to educate kindergartners and their families about the importance of choosing healthy locally produced foods.

Community. Although these local actions focused directly on schools and ECE settings, several community programs were implemented that supported these efforts. The Healthy Corner Store Initiative, targeting the lowest income zip codes in Philadelphia, started as a pilot in 2004 with 24 stores. The initiative is now citywide impacting $>600$ small stores. It increases the availability and awareness of healthy foods in neighborhood stores, offers training and technical assistance to store owners, and provides nutrition education to schools near the stores. A second community program, the Philadelphia Urban Food and Fitness Alliance (PUFFA), is a community-driven initiative to explore where systems change could make a difference in Philadelphia. It was formed in 2005 as a result of a $\$ 1.2$ million grant to improve access to healthy foods and play spaces and to advocate for policy changes. PUFFA developed and implemented a community-driven action plan to improve the food system in Philadelphia schools, create opportunities for active living in the natural and built environment, and create a healthy community food system. These initiatives occurred locally across the city and within specific neighborhoods.

Interactions within and across multiple levels of the SEM: engagement, efficiency, and leveraging resources. Growing concern over high childhood obesity rates and a proposed $\$ 43$ million exclusive "pouring contract" (i.e., the school district receives money in exchange for marketing and selling specific brands of beverages) for Philadelphia schools led The Food Trust to convene a Comprehensive School Nutrition Task Force (Task Force) in 2001. The Task Force was made up of $>40$ groups and individuals representing the interpersonal, organizational, community, and systems levels of the SEM. The SDP Wellness Policy grew out of the work of the Task Force in 2001. 
Parents and teachers were heavily involved in developing, implementing, and increasing public awareness about the wellness policy, and a coordinated media effort between the public relations department of the school district, school members, city officials, and State legislators led to increased public awareness about the wellness policy.

Interactions between community and city agencies: leveraging resources. PUFFA, the community alliance in Philadelphia, shared its community needs assessment with the Philadelphia Department of Public Health, which the health department then built into goals and strategies for their Communities Putting Prevention to Work grant application and activities. PUFFA also helped to start the Common Market, a food distributor that helps connect local farms to the community, by giving them their first grant.

\section{Anchorage, $A K$}

Between 2003-2004 and 2010-2011, the Anchorage School District (ASD) saw a statistically significant decline in obesity among children in kindergarten, first and third grades. Obesity declined from $18.0 \%$ to $17.6 \%$ over this time, representing a $2.2 \%$ relative decrease. ${ }^{19}$

School and ECE setting. Several childhood obesity prevention activities took place in Anchorage and peaked between 2004/2005 and 2008/2009. Improvements to the municipal code governing child care licensing and the development of ASD wellness policies both contributed to improvements in children's environments that are important to preventing obesity and related illnesses.

Strategies occurring in the ECE setting during this time period may have had substantial impact on young children and their families. The 2004 Anchorage municipal child care licensing code change required more frequent and vigorous PA for children in all child care centers and child care homes in Anchorage, which may have played a role in establishing healthy behaviors and body for those children with a decline in obesity. The PA and nutrition programs/ curricula implemented in Kids Corp Head Start Centers, such as Nike Go, Color Me Healthy, and I Am Moving, I Am Learning, had strength in that they were required curricula for all Kids Corp Head Start Centers, which represent the majority of Head Start centers in Anchorage.

Policy improvements in the ASD focusing on student nutrition, PE, and health and wellness occurred. In 2005, the ASD implemented the Wellness Initiative that included the formation of a wellness committee, a wellness policy, and an accompanying 6-year wellness plan. In 2006, the ASD implemented its school wellness policy district wide, which included a soda ban, restrictions on foods sold in school fundraisers, and vending machine controls. The policy was thoroughly implemented and introduced through systematic, school district-wide training (including a toolkit) for principals; school nurses; and health, PE, and other teachers.
And in 2008, ASD introduced health and wellness education in grades $\mathrm{K}-6$, including the addition of 22 dedicated health and wellness teachers.

Community. At the community level, the Healthy Futures project and the Mayor's Task Force on Obesity and Health provided community-based opportunities for collaborative. Healthy Futures was started in 2003 by a community parent advocate who was concerned about the obesity epidemic. The Mayor's Task Force on Obesity and Health was a community-wide effort with representation from schools, ECEs, and community institutions and organizations. This Task Force convened around the time of the ASD wellness committee, and the two worked collaboratively to implement both the School Wellness 6-Year Plan and the Mayor's Task Force 10-Year Plan on Obesity and Health.

Interactions between schools and local government: efficiency. Collaborative between the Mayor's Task Force on Obesity and Health and the Anchorage School District Wellness Committee Policy and 6-Year Plan was widely seen as the impetus for efforts that may have led to COBD in Anchorage. Nationally, State reports of childhood obesity burden brought focused attention to the issue in Anchorage. At the same time, the Mayor's Task Force and School Wellness Committee were forming. Members of both groups worked collaboratively to align goals and policies that resulted in focused and comprehensive efforts to confront childhood obesity both across the community and in the schools of Anchorage, and both the mayor and school superintendent were vocal proponents of these efforts. Because Anchorage is considered a tight-knit community and comprehensive change occurred all at once, it was thought that these efforts had a larger impact. A respondent summed it up this way: "A willing board, a willing city, a willing mayor-all the things aligned. That's the major takeaway from Anchorage. When you get everyone speaking the same language at the same time, you can have a major impact."

\section{Discussion}

The COBD examined four communities that reported small declines in childhood obesity, providing a descriptive overview of each community-what happened and how. It is the first step in better understanding what initiatives are important in addressing childhood obesity and how communities can collaborate to promote healthy environments. However, the retrospective and exploratory nature of the project limits our ability to attribute causation or assess fidelity of the interventions. In addition, although COBD collected information on those policies and programs enacted in each community, the resources needed to effectively implement and sustain these efforts were not included, limiting our ability to better understand the costs of these programs or whether efforts at the local level were 
sustained. Limitations of this study can be found in more detail in this supplement. ${ }^{15}$

The four communities studied showed declines in childhood obesity even though there were differences in size and context. New York and Philadelphia are large urban areas with a history of supportive leaders and agencies. In contrast, Granville County and Anchorage are smaller more isolated areas with less collaborative history. Yet in all four communities, childhood obesity was reduced between two time points. Each community was unique in its approach but all had cross-sector partnerships working together in coordinated comprehensive ways (Fig. 1). In some communities, those efforts led to buy-in, engagement, and support of involved parties both within and across levels of the SEM. In others, they resulted in leveraged resources that supported increased collaborative and greater efficiency.

For New York City, champions with decision-making power were strong supporters of a comprehensive approach to health and wellness. This promoted commitment and collaborative across New York City government agencies, which helped promote the smooth integration of programs and policies across the SEM levels and encouraged health-promoting policies within and across agencies. In Granville County, North Carolina, supportive state policies and programs, some with dedicated funding, provided opportunities for local action that may not have been available otherwise, and sharing resources allowed for leveraging of funds that increased opportunities for environmental improvements. Both Philadelphia and Anchorage provide examples of coordinated local action that appeared to drive organizations' work to improve nutrition and increase PA. The SDP was an innovator in policies that were adapted to fit the school district and was a leader in implementing a comprehensive district-wide school wellness policy that was supported by coordinated communitydriven programs. In Anchorage, coordination between the School Wellness committee and the Mayor's Task Force on Obesity and Health led to a comprehensive approach to implementing both the School Wellness and Mayor's Task Force plans.

\section{Conclusions}

Models like the SEM offer a framework for better understanding the multiple and interacting programs and activities that determine health behaviors, and are being used more often to implement comprehensive approaches to addressing public health problems such as childhood obesity. Yet the increasing use of these models requires a better understanding of exactly how these levels of influence operate, including what key multilevel factors are needed and how those factors interact among the different levels of influence.

The communities in this study implemented programs and policies over time that worked at different levels to potentially improve obesity outcomes. Studying these communi- ties through an SEM lens can provide important information about factors and processes that may be present in successful interventions. As public health continues to adopt ecological frameworks to address obesity, examining successful communities can improve our understanding of how multiple levels of influence operate, the assets and people needed as change makers, and what may drive behavior and health outcomes.

\section{Acknowledgments}

The National Collaborative for Childhood Obesity Research (NCCOR) is a private and public partnership between the CDC, NIH, Robert Wood Johnson Foundation (RWJF), and USDA that provided technical assistance for this study. FHI360 serves as the Coordinating Center for NCCOR. ICF served as the lead contractor for the study. The authors thank NCCOR members Melissa Abelev, Veronica Uzoebo, and Ruth Morgan of the Food and Nutrition Service of USDA for participation in the study advisory committee. The authors thank the many site key stakeholders for their time and cooperation with interviews and site program documentation and the study site visitors who conducted the interviews and drafted the site summary reports, specifically Stacey Willocks, MS; Stephanie Frost, PhD.; Michael Greenberg, JD, MPH; Katherine Reddy, MS; and Joseph Fruh, BS. The findings and conclusions in this report are those of the authors and do not necessarily represent the official position of the CDC, NIH, or any of the other project agencies. The RWJF funded this project (ID No. 71772-Analyzing the Signs of Progress in Childhood Obesity).

\section{Author Disclosure Statement}

No competing financial interests exist.

The authors did not report any conflicts of interest or financial disclosures. The findings and conclusions in this report are those of the authors and do not necessarily represent the official position of the Centers for Disease Control and Prevention, ICF, the National Institutes of Health, or the Robert Wood Johnson Foundation.

\section{References}

1. McLeroy K, Bibeau D, Steckler A, et al. An ecological perspective on health promotion programs. Health Ed Qtrly 1988;15:351-377.

2. Ohri-Vachaspati P, DeLia D, DeWeese, R, et al. The relative contribution of layers of the Social Ecological Model to childhood obesity. Pub Health Nutr 2015;18:2055-2066.

3. Lytle L. Examining the etiology of childhood obesity: The IDEA study. Am J Comm Psych 2009;44:338.

4. Ohri-Vachaspati P, DeWeese R, Crespo N, et al. Social Ecological Model (SEM) and childhood obesity: What do the data suggest? FASEB J 2013;27(Suppl 1):842.3.

5. Pérez-Escamilla R, Kac G. Childhood obesity prevention: A lifecourse framework. Intl J Obesity 2013;3(Suppl 1):S3-S5. 
6. Stark C, Devine C, Dollahite J. Characteristics associated with the application of an ecological approach to preventing childhood obesity. Pub Health Nutr 2017;20:174-182.

7. Sallis J, Cervero R, Ascher W, et al. An ecological approach to creating more physically active communities. Ann Rev Pub Health 2006;27:297-322.

8. McNeill L, Wyrwich $\mathrm{K}$, Brownson $\mathrm{R}$, et al. Individual, social environmental, and physical environmental influences on physical activity among black and white adults: A structural equation analysis. Ann Behav Med 2006;31:36-44.

9. Story, M, Kaphingst K, O'Brien R, et al. Creating healthy food and eating environments: Policy and environmental approaches. Ann Rev Pub Health 2008;29:253-272.

10. Comstock C, Kattelmann K, Zstrow M, et al. Assessing the environment for support of youth physical activity in rural communities. Jr Nut Ed and Behav 2016;48:234.

11. Dooyema C, Jernigan J, Lowry Warnock A, et al. Childhood Obesity Declines Project: A review of enacted policies. Child Obes 2018;14:S22-S31.

12. Ottley PG, Dawkins-Lyn N, Harris C, et al. Childhood Obesity Declines Project: An exploratory study of strategies identified in communities reporting declines. Child Obes 2018;14:S12-S21.

13. Kettel Khan L, Ottley P, Harris C, et al. Childhood Obesity Declines Project: A different methodology. Child Obes 2018;14: S5-S11.

14. Trust for America's Health. $F$ as in fat. How obesity policies are failing in America. Available at http://healthyamericans.org/ reports (last accessed September 14, 2015).
15. Brill A. The long-term returns on obesity prevention policies Available at https://depts.washington.edu/waaction/tools/docs/rwjf_ returns_report.pdf (last accessed September 14, 2015).

16. Centers for Disease Control and Prevention. Obesity in K-8 students-New York City, 2006-07 to 2010-11 school years. MMWR 2011;60:1673-1678.

17. Granville-Vance District Health Department. Granville \& Vance 2012 state of the county health report. Available at http://gvph.org/ wp-content/uploads/2014/08/SOTCH-2012-final_12-20-12.pdf (last accessed September 14, 2015).

18. Robbins J, Mallya G, Polansky M, et al. Prevalence, disparities, and trends in obesity and severe obesity among students in the Philadelphia, Pennsylvania, school district, 2006-2010. Prev Chronic Dis 2012;9:120118.

19. Centers for Disease Control and Prevention. Obesity in K-7 studentsAnchorage, Alaska, 2003-04 to 2010-11 school years. MMWR 2013;62:426-430.

Address correspondence to: Jan Jernigan, PhD

Division of Nutrition, Physical Activity, and Obesity Centers for Disease Control and Prevention 4770 Buford Highway, F-77 Atlanta, GA 30341

E-mail: ddq8@cdc.gov 